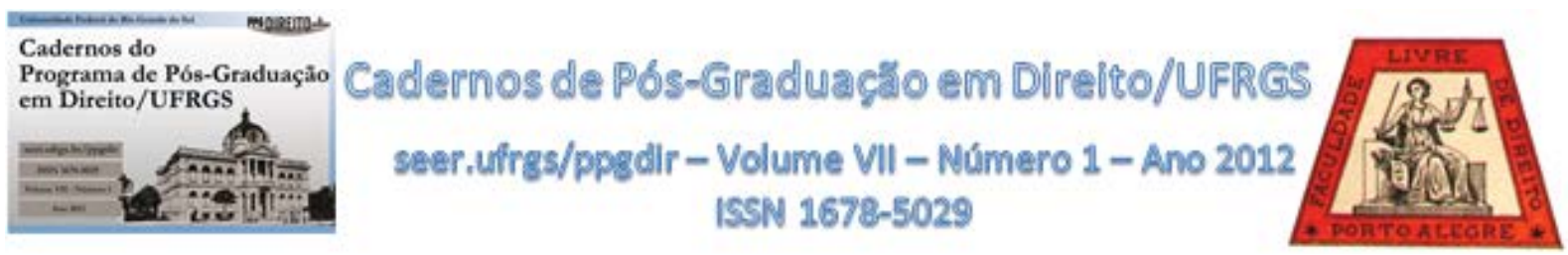

\title{
CORRUPÇÃO: O PAPEL DOS CONTROLES EXTERNOS - TRANSPARÊNCIA E CONTROLE SOCIAL. UMA ANÁLISE DE DIREITO E ECONOMIA
}

\author{
CORRUPTION: EXTERN CONTROL ROLES - TRANSPARENCY AND SOCIAL
}

CONTROLE. A LAW AND ECONOMICS ANALYSIS

Professor Cesar Santolim

Sumário: 1 . O controle externo. 2. Corrupção. 3. Transparência e controle social. 4. As estruturas dos órgãos de controle externo. 5. A corrupção na percepção da "Criminal Law and Economics". 6. Os Tribunais de Contas no Brasil e o combate à corrupção. Conclusão.

Resumo: É propósito deste artigo tratar das estruturas de controle administrativo/parlamentar ("órgãos de controle externo"), com suas particularidades, dando ênfase à solução que corresponde à tradição constitucional brasileira, e avaliar sobre a capacidade destas instituições serem eficientes no combate à corrupção.

Palavras-chave: Corrupção; controles externos; transparência; tribunal de contas; direito e economia.

Abstract: The purpose of this article is to study the administrative control structures / parliamentarian ("external control organs"), with its particularities, emphasizing the Brazilian constitutional traditional solution, and evaluate the ability of these institutions to be effective against corruption.

Keywords: corruption; external control; transparency; audit office; law and economics.

\section{O CONTROLE EXTERNO}

O controle dos atos da administração pública pode ser feito de diversas formas, que variam segundo cada sistema político-jurídico. Fundamentalmente, se reconhece ${ }^{1}$ a existência de três campos específicos para essa atividade (administrativo, parlamentar e judiciário), correspondendo, lato sensu, a tripartição clássica de Poderes, no Estado Constitucional.

\footnotetext{
${ }^{1}$ MOREIRA NETO, Diogo de Figueiredo. Curso de Direito Administrativo, $14^{\mathrm{a}}$ ed., Rio de Janeiro: Forense, 2005, p. 564.
} 
Na realidade, e especialmente quando se trata do combate à corrupção, estas formas de controle interagem, seja porque há expressa previsão nesse sentido, na estrutura jurídica ${ }^{2}$, seja porque, por razões operacionais, se torna conveniente um trabalho de cooperação. Também não se pode desconsiderar que há níveis intermediários de exercício do poder estatal, mediando a tripartição clássica, o que permite cogitar de competências para o controle distribuídas entre outros órgãos (agências reguladoras, Ministério Público, Tribunais de Contas, Auditorias e Controladorias-Gerais, organismos de investigação policial, entre outros).

Neste contexto de pluricontrole (às vezes, redundante), a designação “órgãos de controle externo” tem sido reservada às instituições cuja atribuição precípua (ou até exclusiva) é a fiscalização do uso dos recursos públicos pela Administração ${ }^{3}$.

Parece certo que uma característica do Estado Constitucional ${ }^{4}$ democrático é exatamente o controle do poder.

Robert DAHL, em "Sobre a Democracia” ${ }^{5}$, ao analisar quais seriam os critérios de um processo democrático (participação efetiva, igualdade de voto, entendimento esclarecido, controle do programa de planejamento e inclusão dos adultos), assim define o quarto critério, a partir da perspectiva de um grupo (dos “maiores proprietários”, minoritário, nos termos do segundo critério) que se pretenda impor, do ponto de vista de seus interesses:

"Eles apresentam uma solução criativa: uma constituição que corresponderia satisfatoriamente aos três primeiros critérios, e que, até esse ponto, pareceria plenamente democrática. No entanto, para anular esses critérios, propõem exigir que nas reuniões gerais os membros pudessem apenas discutir e votar sobre questões já incluídas no programa por uma comissão executiva; a participação nesse comitê executivo está aberta apenas aos maiores proprietários. Controlando o programa de governo, essa minúscula “igrejinha” teria a certeza de que a associação jamais atuará contra seus interesses, porque jamais permitirá qualquer proposta que se mostre contrária a seus interesses”.

\footnotetext{
${ }^{2}$ No Brasil, por exemplo, o $\S 1^{0}$ do artigo 74 da Constituição Federal vincula os responsáveis pelo controle interno (que é administrativo) a dar ciência de irregularidades ao Tribunal de Contas (que efetua controle administrativo/parlamentar). Já as decisões dos Tribunais de Contas de que resulte débito ou multa têm eficácia de título executivo, que dá suporte à uma ação judicial (controle judiciário).

${ }^{3}$ Veja-se, a propósito, o site da INTOSAI (International Organisation of Supreme Audit Institutions): www.intosai.org.

${ }^{4}$ Por "Estado Constitucional” entende-se a noção de Joaquim José Gomes CANOTILHO: "O Estado constitucional é "mais" que o Estado de direito. O elemento democrático não foi introduzido apenas para "travar" o poder (to check the power); foi também reclamado pela necessidade de legitimação do mesmo poder (to legitimize State power)...” (in Direito Constitucional e Teoria da Constituição, $7^{\mathrm{a}}$ ed., Coimbra: Almedina, 2003, p. 100.

${ }^{5}$ Brasília: Editora UnB, 2001, p. 52.
} 
Não há maior "programa de planejamento" do que aquele definido pelas peças orçamentárias (no Brasil, Leis do Plano Plurianual - PPA -, de Diretrizes Orçamentárias LDO - e Orçamentária Anual - LOA), que tratam exatamente sobre o uso dos recursos públicos, cujo controle é feito precipuamente pelos órgãos de controle externo. Assim, o controle dos recursos públicos (receitas e gastos) é uma das formas mais efetivas de controle do poder estatal, e é condição para a manutenção da democracia. É possível afirmar, sem grande receio de equívoco, que não há política pública relevante que se possa executar sem a utilização de recursos públicos, de modo que a fiscalização sobre o correto uso destes mesmos recursos é decisiva na determinação do funcionamento do poder do Estado.

\section{CORRUPÇÃO}

Já a corrupção é definida por Gianfranco PASQUINO como “fenômeno pelo qual um funcionário público é levado a agir de modo diverso dos padrões normativos do sistema, favorecendo interesses particulares em troco de recompensa. Corrupto é, portanto, o comportamento ilegal de quem desempenha um papel na estrutural estatal...” ${ }^{6}$. Logo, os mecanismos de controle externo da Administração Pública desempenham um papel fundamental no combate à corrupção, pois que a maior ou menor eficiência destes mecanismos será fator determinante (embora não o único) para que os níveis de corrupção sejam também maiores ou menores. E a existência de corrupção implica no desperdício de recursos (públicos e privados) que poderiam ser alocados em atividades geradoras de maior bem-estar social. Daí a importância econômica de sua redução (para além de razões de ordem estritamente moral).

O Brasil está classificado (2011) na 73ª posição no ranking da Transparência Internacional sobre percepção de corrupção (entre 183 países), com um índice correspondendo a 3,8 (em uma escala de 0 - altamente corrupto - a 10 - altamente livre de corrupção) ${ }^{7}$.

\footnotetext{
${ }^{6}$ Verbete “corrupção” in Dicionário de Política, 9a ed., Brasília: UnB, 1997, p. 285.

${ }^{7}$ Dados obtidos no site "http://www.transparency.org/cpi2011/results", em 10/11/2012.
} 


\section{TRANSPARÊNCIA E CONTROLE SOCIAL}

Como já foi dito, entre os critérios que definem o processo democrático estão a “participação efetiva” e o "entendimento esclarecido" ${ }^{8}$, e nenhum dos dois critérios pode ser plenamente satisfeito sem a observância do princípio da transparência e da existência de controle social.

A “transparência” (que é a qualidade dos objetos que se deixam atravessar pela luz, permitindo que se veja, com nitidez, o que está do outro lado) tem fundamentos político (no ideal democrático, proporcionando um novo status à cidadania), jurídico (princípio constitucional implícito, relativo ao dever do Estado de mostrar-se em forma e conteúdo) e social (pois é condição para o controle social efetivo) ${ }^{9}$. Coloca-se, portanto, como uma dimensão tanto do Estado de Direito como da Democracia, princípios imanentes à nossa ordem constitucional.

Joaquim José Gomes CANOTILHO ${ }^{10}$ lembra que, além de um modo “positivo” para justificar a democracia (“Fórmula de Lincoln”: governo do povo, pelo povo e para o povo), há outro ("negativo", ou "Fórmula de Popper”: forma ou técnica processual de seleção e destituição pacífica de dirigentes). Segundo o autor português "a justificação da democracia em termos negativos e basicamente procedimentais pretende por em relevo que a essência da democracia consiste na estruturação de mecanismos de seleção dos governantes e, concomitantemente, de mecanismos de limitação prática do poder, visando criar, desenvolver e proteger instituições políticas adequadas e eficazes para um governo sem as tentações da tirania”. É por isso, segundo o mesmo autor, que “essa compreensão do princípio democrático como princípio de controle tem sido agitada em tempos recentes a propósito da limitação temporal de mandatos em cargos eletivos ('problema dos dinossauros políticos') e da capacidade de resposta do sistema político-constitucional à corrupção política”.

\footnotetext{
${ }^{8}$ Ainda segundo Robert DAHL, op. cit., p. 49: por participação efetiva se deve entender que "antes de ser adotada uma política pela [associação], todos os membros devem ter oportunidades iguais e efetivas para fazer os outros membros conhecerem suas opiniões sobre qual deveria ser esta política" e por entendimento esclarecido que "dentro de limites razoáveis de tempo, cada membro deve ter oportunidades iguais e efetivas de aprender sobre as políticas alternativas importantes e suas prováveis consequências”.

${ }^{9}$ Para uma melhor compreensão sobre a noção de transparência veja-se "O Princípio da Transparência e o Direito Fundamental à Informação Administrativa”, de Evandro T. HOMERCHER (Porto Alegre: Padre Reus, 2009).

${ }^{10}$ Op. cit., p. 291.
} 
Esta proximidade entre a noção de transparência e o enfrentamento da corrupção, pela valorização de uma justificação negativa do princípio democrático ${ }^{11}$, ganha ainda mais evidência quando se destaca que, sob a perspectiva de seu fundamento social, a transparência é requisito para um efetivo controle social da Administração Pública. Somente quem está adequadamente informado pode realizar controle, pois não se pode controlar o desconhecido. Para que os integrantes de uma sociedade, de forma individual ou coletiva, possam de fato monitorar aquilo que, em sua representação, é realizado pelos governantes, é preciso que as ações administrativas sejam transparentes, isto é, permitam que se identifique, com nitidez, o seu objeto. Neste sentido, há vários mecanismos disponíveis, alguns deles alçados à proteção constitucional (liberdade de expressão e informação, liberdade de associação, liberdade de manifestação do pensamento, princípios constitucionais da publicidade e da legalidade estes, quanto à Administração Pública, no caput do artigo 37 da Constituição Federal), dentre os quais está o controle externo exercido pelos Tribunais de Contas.

A entrada em vigor, no Brasil, da Lei Complementar nº 131/2009 (apelidada de "Lei da Transparência Fiscal”) é uma evidência desta relação. Muito embora já se pudesse encontrar na Lei Complementar n 101/2000 (“Lei da Responsabilidade pela Gestão Fiscal”) alguns elementos indicadores da importância do controle social sobre as ações da Administração Pública (artigo 48), com as modificações introduzidas em 2009 o tratamento jurídico do tema ganhou nova dimensão. Não somente foram explicitadas novas formas de efetivação do princípio da transparência como foi mantida a competência dos Tribunais de Contas para aferição sobre o cumprimento destas medidas, e que decorre do contido no artigo 59 da já referida LC nº 101/2000.

Ainda mais recentemente, a Lei $\mathrm{n}^{0}$ 12.527/2011 ("Lei de Acesso a Informações") igualmente veio a reforçar a efetividade dos valores relacionados com a noção de transparência.

\section{AS ESTRUTURAS DOS ÓRGÃOS DE CONTROLE EXTERNO}

\footnotetext{
${ }^{11}$ Não há Democracia sem controle, ainda que a afirmação, a primeira vista, pareça paradoxal, quando se sabe que a Democracia é tida como o "regime das liberdades". Mas, de fato, não há mesmo "liberdade" sem uma estrutura normativa que preceda as escolhas. Logo, não há "liberdade” sem controle. Acerca do assunto: BERLIN, Isaiah ("Dos Conceptos de Libertad”, in "Cuatro Ensayos sobre La Libertad”, versão de Julio BAYÓN, Madrid: Alianza Editorial, 1998).
} 
Há dois grandes grupos que contêm os principais órgãos de controle externo, considerando os modelos político-jurídicos no cenário europeu, norte e latino americano e da Oceania:

a) países que adotam um órgão central de controle de recursos públicos (Australian National Audit Office, na Austrália, General Accounting Office, nos EUA, National Audit Office, no Reino Unido, Office of the Auditor General, no Canadá, Auditoría General de la Nación, na Argentina, Controloría General de la República, na Bolívia, Colômbia, Costa Rica, Peru, Venezuela, Panamá, Rigsrevisionen, na Dinamarca, entre outros);

b) países que adotam uma corte (modelo judicialiforme) para o controle externo (França, Finlândia, Espanha, Uruguai, Portugal, Bélgica, Itália, Áustria e Brasil - pela ordem cronológica de criação dos respectivos Tribunais -, também entre outros) ${ }^{12}$.

Dentro de cada grupo, há importantes variações (maior ou menor autonomia dos órgãos centrais de controle e dos Tribunais, vinculação estrutural ao Poder Executivo, ao Poder Legislativo - como ocorre no Brasil - ou, até, ao Poder Judiciário - art. 214 da Constituição Portuguesa).

A tradição constitucional brasileira é a da vinculação dos Tribunais de Contas ao Poder Legislativo. Desde a criação do Tribunal de Contas da União (Decreto $n^{\circ}$ 966-A, de 7 de novembro de 1890), todas as Constituições republicanas do Brasil registram os Tribunais de Contas como órgão de existência necessária, destinado ao controle dos recursos públicos, e vinculado estruturalmente ao Poder Legislativo. Apesar desta vinculação, os Tribunais de Contas, de fato, no atual modelo constitucional, constituem o que se convencionou chamar de “categoria intermédia” entre os poderes (assim como, por exemplo, o Ministério Público, que, apesar de vinculado estruturalmente ao Poder Executivo, conserva sua autonomia administrativa, financeira e funcional).

A autonomia dos Tribunais de Contas vem realçada com a norma ( $\S \S 3^{\circ}$ e $4^{\circ}$ do artigo 73 da Constituição Federal) que garante aos seus membros (Ministros, Conselheiros e Auditores, Substitutos de Ministros e Conselheiros) as garantias, prerrogativas e os impedimentos dados aos membros do Poder Judiciário, o que assegura um elevado grau de independência nas suas ações. Ainda que predomine o critério político na composição da

\footnotetext{
12 Para um melhor detalhamento sobre o tema, veja-se “O Controle da Gestão Pública”, de Helio Saul MILESKI ( $2^{\mathrm{a}}$ ed., revisada, atualizada e aumentada. Belo Horizonte: Forum, 2011)
} 
estrutura superior destes órgãos ${ }^{13}$ (o que, diga-se de passagem, também é característica dos Tribunais Superiores, no Poder Judiciário), a existência destas garantias e prerrogativas protege os membros dos Tribunais de Contas (e, essencialmente, protege a própria sociedade, que é a destinatária final da sua atividade) quanto à pressões políticas, pois, uma vez empossados, os membros dos Tribunais de Contas são vitalícios e inamovíveis.

\section{A CORRUPÇÃO NA PERCEPÇÃO DA “CRIMINAL LAW AND ECONOMICS”}

A abordagem do "Direito e Economia"14 acerca da corrupção a vê mais como um problema de incentivos e organização do que como de moral pública ou de normas ${ }^{15}$. A corrupção é tratada como uma “atividade mútua”: uma transação onde os negociantes são, ao mesmo tempo, vendedores e compradores, e as partes são conduzidas pelo seu próprio interesse (privado) ao invés do “interesse público”. Isso não necessariamente implica em “indignidade moral”, mas apenas significa que o desenho das organizações governamentais precisa compensar estes incentivos privados, se quiser estar protegido contra o oportunismo e a exploração. Sob a perspectiva dos seus custos sociais, o dano causado pela corrupção pode ser dividido em dois componentes: o "dano institucional” (que repercute na baixa reputação da Administração Pública) e o “dano efetivo” (por exemplo, o que decorre de não ser contratada uma obra pública pelo seu valor correto, diante de superfaturamento decorrente da existência de corrupção).

\footnotetext{
${ }^{13}$ Dos nove Ministros do Tribunal de Contas da União, seis são escolhidos pelo Congresso Nacional e três pelo Presidente da República, sendo, destes, um de sua livre escolha e os outros dois de listas tríplices, elaboradas pelo próprio Tribunal, e compostas de Auditores, Substitutos de Ministros, e de integrantes do Ministério Público que atua junto ao TCU, respectivamente; dos sete Conselheiros dos Tribunais de Contas dos Estados e dos Municípios, quatro são escolhidos pela Assembléia Legislativa e três pelo Governador do Estado, com critério semelhante ao do TCU: um é de livre escolha e os outros dois vêm de listas tríplices, elaboradas pelo próprio Tribunal, e compostas de Auditores, Substitutos de Conselheiros, e de integrantes do Ministério Público que atua junto ao TCU

${ }^{14}$ A disciplina de "Law and Economics" ("Direito e Economia") é uma das mais importantes abordagens teóricas no pensamento norte-americano, desde a segunda metade do século passado. Hoje repercute também no pensamento europeu e latino-americano. Recentes trabalhos publicados no Brasil traduzem esta expansão (citese a tradução da obra de Robert COOTER e Thomas ULEN - "Direito \& Economia", Porto Alegre, Bookman: 2010 -, e os trabalhos organizados por Bruno Meyerhof SALAMA - "Direito e Economia - Textos Escolhidos", São Paulo: Saraiva, 2010 - e por Luciano Benetti TIMM - "Direito e Economia no Brasil", São Paulo: Atlas, $2012-)$.

${ }^{15}$ BOWLES, Roger, "Corruption”, in "Criminal Law and Economics", Encyclopedia of Law and Economics, vol. 3, 2a ed., Nuno GAROUPA (ed.), Northampton, MA: Edward Elgar Publishing, 2009.
} 
Um dado importante, nesta análise, é o de que a corrupção é, via de regra, um modelo de três partes: exige o acordo entre um elemento que integra a Administração Pública com outro, fora dela. Os benefícios deste acordo são partilhados entre estas duas partes as expensas do erário (terceira parte), e, mediatamente, da sociedade.

Como assinala Roger Bowles, ao tratar dos “custos da corrupção”, é possível identificar quatro situações: rent-seeking costs, custos para a vítima, custos na antecipação do crime e custos do sistema de justiça criminal. Os três últimos são facilmente constatáveis, muito embora, assinala este mesmo autor, em se tratando de corrupção os custos para a vítima (no caso, o erário) são substancialmente mais difusos do que quando se está diante de outra forma de ação criminosa (furto, roubo ou lesão pessoal). Se alguém corrompe um servidor público para antecipar-se a outros indivíduos na prestação de um serviço (concessão de um documento, por exemplo), o prejuízo é suportado, na realidade, por todos os demais indivíduos que foram preteridos por essa antecipação, muito embora o serviço, na realidade, devesse ser prestado, de outra maneira. Menos óbvios são os custos dos "agentes de corrupção" (rent-seeking costs), mas nem por isso menos importantes. Tanto o "corrupto" quanto o "corruptor” tem que dedicar parte dos seus "ganhos” com a corrupção para proteger os seus interesses. Como as transações feitas em situação de corrupção são ilegais, não é dado aos “negociadores” se valerem das formas de proteção que o sistema jurídico outorga ao cumprimento dos contratos, o que significa que estas garantias deverão ser obtidas de outras maneiras. Altos custos de transação, aqui, podem funcionar como mecanismo eficiente de desestímulo à corrupção.

\section{OS TRIBUNAIS DE CONTAS NO BRASIL E O COMBATE À CORRUPÇÃO}

Ao estabelecer, no seu artigo 71, que "o controle externo, a cargo do Congresso Nacional, será exercido com o auxílio do Tribunal de Contas da União”, a Constituição Federal fixou as competências deste órgão, aplicáveis aos demais Tribunais de Contas do país, nos termos do artigo 75 do mesmo texto constitucional:

“...

I - apreciar as contas prestadas anualmente pelo Presidente da República, mediante parecer prévio que deverá ser elaborado em sessenta dias a contar de seu recebimento; 
II - julgar as contas dos administradores e demais responsáveis por dinheiros, bens e valores públicos da administração direta e indireta, incluídas as fundações e sociedades instituídas e mantidas pelo Poder Público federal, e as contas daqueles que derem causa a perda, extravio ou outra irregularidade de que resulte prejuízo ao erário público;

III - apreciar, para fins de registro, a legalidade dos atos de admissão de pessoal, a qualquer título, na administração direta e indireta, incluídas as fundações instituídas e mantidas pelo Poder Público, excetuadas as nomeações para cargo de provimento em comissão, bem como a das concessões de aposentadorias, reformas e pensões, ressalvadas as melhorias posteriores que não alterem o fundamento legal do ato concessório;

IV - realizar, por iniciativa própria, da Câmara dos Deputados, do Senado Federal, de Comissão técnica ou de inquérito, inspeções e auditorias de natureza contábil, financeira, orçamentária, operacional e patrimonial, nas unidades administrativas dos Poderes Legislativo, Executivo e Judiciário, e demais entidades referidas no inciso II;

$\mathrm{V}$ - fiscalizar as contas nacionais das empresas supranacionais de cujo capital social a União participe, de forma direta ou indireta, nos termos do tratado constitutivo;

VI - fiscalizar a aplicação de quaisquer recursos repassados pela União mediante convênio, acordo, ajuste ou outros instrumentos congêneres, a Estado, ao Distrito Federal ou a Município;

VII - prestar as informações solicitadas pelo Congresso Nacional, por qualquer de suas Casas, ou por qualquer das respectivas Comissões, sobre a fiscalização contábil, financeira, orçamentária, operacional e patrimonial e sobre resultados de auditorias e inspeções realizadas;

VIII - aplicar aos responsáveis, em caso de ilegalidade de despesa ou irregularidade de contas, as sanções previstas em lei, que estabelecerá, entre outras cominações, multa proporcional ao dano causado ao erário;

IX - assinar prazo para que o órgão ou entidade adote as providências necessárias ao exato cumprimento da lei, se verificada ilegalidade;

$\mathrm{X}$ - sustar, se não atendido, a execução do ato impugnado, comunicando a decisão à Câmara dos Deputados e ao Senado Federal;

XI - representar ao Poder competente sobre irregularidades ou abusos apurados.

Apenas a primeira das competências fixadas no texto constitucional coloca os Tribunais de Contas na condição de órgãos de auxílio ao Poder Legislativo (e quem "presta auxílio”, em situação particular, não é “auxiliar”, que é condição permanente). No exercício desta competência, é onde menos se revela a possibilidade concreta do enfrentamento da corrupção, exceto quando se tratar de um quadro sistêmico. É que, aqui, as Cortes de Contas se limitam a uma manifestação (favorável ou desfavorável) acerca da globalidade das contas de cada Gestor Público (no caso, chefes do Poder Executivo), onde a identificação de situações de corrupção somente serão consideradas se puderem ser vistas como perpassando, genericamente, todas as ações da Administração.

Já nos demais casos, quando os Tribunais de Contas exercem suas competências com exclusividade (daí se constituírem nas instituições principais no controle externo dos recursos públicos), as Cortes de Contas podem se valer de políticas de combate à corrupção, 
considerando, fundamentalmente, a ideia de que o aumento nos custos de transação dos partícipes das atividades de corrupção é fator determinante na redução dos seus índices.

No julgamento dos responsáveis por “dinheiros, bens ou valores públicos” é ampla a possibilidade percepção de situações de corrupção e quanto mais efetiva for a ação fiscalizatória maiores serão os rent-seeking costs da corrupção. O controle da receita e da despesa públicas, nos seus aspectos formais e materiais, conduz, necessariamente, a um quadro onde a possibilidade da corrupção é reduzido, mormente quando a ação dos Tribunais de Contas é acompanhada de medidas adotadas por outros órgãos com competências constitucionais específicas, relacionadas com a matéria (autoridades policiais, Ministério Público, Poder Judiciário).

A obtenção de melhores resultados, nesta tarefa, é facilitada pelas possibilidades oferecidas pelo texto constitucional, quando se afirma que os Tribunais de Contas são competentes para "realizar ... inspeções e auditorias de natureza contábil, financeira, orçamentária, operacional e patrimonial” e "fiscalizar a aplicação de quaisquer recursos repassados pela União mediante convênio, acordo, ajuste ou outros instrumentos congêneres, a Estado, ao Distrito Federal ou a Município”.

A amplitude da atividade fiscalizatória, somada a possibilidade que têm as Cortes de Contas de se auto-regrarem, quanto aos seus procedimentos internos (e que decorre do disposto no artigo 96, I, da Constituição Federal), lhes dá, do ponto de vista jurídico, um espaço importante no combate à corrupção.

O mesmo se pode dizer da apreciação, para fins de registro, da "legalidade dos atos de admissão de pessoal ... bem como a das concessões de aposentadorias, reformas $e$ pensões”, pois esta é outra fonte importante de corrupção, na medida em que um controle deficiente (ou, até, ausente) destes atos administrativos abre a possibilidade de um semnúmero de situações onde podem ocorrer, especialmente, lesões ao princípio da impessoalidade, também de matriz constitucional. A correção das contratações temporárias e das admissões para cargos de provimento efetivo (e empregos públicos), bem como dos atos de inativação de servidores públicos, é garantia de que não houve espaço para situações de corrupção, pois apenas as situações jurídicas amparadas na lei é que foram respeitadas. Nesta atividade, quanto mais célere for o exame realizado pelos Tribunais de Contas, evitando se criarem situações individuais (ilegais) que acabam protegidas pelo princípio da segurança das relações jurídicas, mais se estará contribuindo para o combate à corrupção. 
Por fim, mas não menos importante, é a possibilidade que têm as Cortes de Contas de fixar débitos (nos casos de mau uso dos recursos públicos) e de impor sanções pecuniárias aos Gestores (ainda que, neste último caso, os valores sejam, às vezes, irrisórios ${ }^{16}$ ). Mais, ainda: conforme o $\S 3^{\circ}$ do artigo 71 da Constituição Federal, os montantes resultantes destes débitos e multas, se não forem satisfeitos pelos que foram responsáveis, permite a emissão de certidão com força de título executivo, com todas as consequências daí decorrentes.

Em decisões recentes ${ }^{17}$, o Supremo Tribunal Federal vem reconhecendo que, no exercício de suas competências, os Tribunais de Contas podem, valendo-se de medidas cautelares, determinar a sustação de medidas administrativas, quando evidenciado o risco de prejuízo ao erário, o que, a toda vista, pode também funcionar como um instrumento valioso no combate à corrupção.

É certo que estas competências constitucionais, para que possam ser exercidas na plenitude, dependem de recursos materiais que nem sempre estão ao alcance dos Tribunais de Contas. Uma maior percepção da sociedade sobre a importância destes mecanismos de controle, todavia, haverá de servir para que esses recursos sejam adequadamente alocados.

\section{CONCLUSÃO}

a) independentemente da estrutura adotada (Tribunais ou Auditorias e Controladorias-Gerais), o controle externo da Administração Pública é uma característica dos sistemas constitucionais contemporâneos;

b) a corrupção (entendida como favorecimento indevido de interesses) existe, em maior ou menor medida, em toda e qualquer organização pública;

c) a transparência e o controle social são mecanismos que influenciam na redução da corrupção;

d) a tradição constitucional brasileira é a de que o controle externo se faz através dos Tribunais de Contas e a Constituição Federal de 1988 reservou-lhes competências específicas;

\footnotetext{
${ }^{16}$ No Rio Grande do Sul, por exemplo, a maior multa que pode ser aplicada a um Administrador é de R\$ 1.500,00, dependendo a alteração deste valor de modificação na legislação local (Lei no 11.424/2000).

${ }^{17} \mathrm{MS} \mathrm{n}^{\circ}$ 24.510/DF, ADI $2633 \mathrm{MC} / \mathrm{RR}$.
} 
e) vista a corrupção como dependente de um sistema eficiente de (des)incentivos, os Tribunais de Contas, no exercício de suas atribuições, podem ser importantes geradores de rent-seeking costs, contribuindo para coibir a corrupção. 